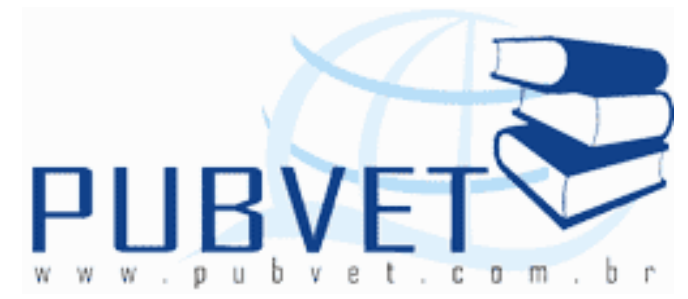

PUBVET, Publicações em Medicina Veterinária e Zootecnia.

\title{
Criopreservação de sêmen equino, um desafio a ser vencido
}

\section{Rodrigo Arruda de Oliveira ${ }^{1}$}

${ }^{1}$ Universidade de Brasília, Faculdade de Agronomia e Medicina Veterinária, Departamento de Reprodução Animal, Campus Universitário Darcy Ribeiro, Instituto Central de Ciências, Ala Sul, Asa Norte, CEP 70910-900, Brasília/DF, Brasil. E-mail: rodrigoarruda@unb.br

\section{Resumo}

Na equinocultura mundial é cada vez maior a utilização do sêmen congelado, devido a recente liberação do seu uso por grande parte das associações de criadores. Entretanto, a fertilidade do sêmen congelado ainda é baixa, e isto dificulta a sua utilização em larga escala. Várias técnicas têm sido testadas para a criopreservação espermática utilizando diferentes velocidades e meios de centrifugação, curvas e meios de congelamento, crioprotetores e suas concentrações, bem como protocolos de descongelamento. Embora vários centros de pesquisa tenham se envolvido em estudos nesta área, ainda não há uma metodologia de congelamento universalmente aceita para esta espécie. Objetivou-se com essa revisão reunir informações, e apresentá-las de forma sintética, sobre as principais limitações encontradas para criopreservação do sêmen de equinos e sua utilização em larga escala.

Palavras-chave: Congelamento de sêmen; espermatozoide; garanhão; recursos genéticos 


\section{Equine frozen semen, a challenge to be overcome}

\section{Abstract}

In world's Equine breed the use of frozen semen is increasing, due to the recent release of its use by most breeders associations. However, the fertility of frozen semen is still low, and this hampers their widespread use. Several techniques have been tested for sperm cryopreservation using different centrifugation speed sand extenders, freezing curves, cryoprotectants and their concentration and thawing protocols. Although several research centers have been exploring this topic, there is still no method of freezing semen universally accepted for this species. The objective of this review to gather information and present it in summary form, on the main limitations encountered in equine semen cryopreservation and its large-scale use.

Keywords: frozen semen; genetic resource; spermatozoa; stallion

\section{Introdução}

A equinocultura no Brasil vem se desenvolvendo muito nos últimos tempos, certos segmentos, como os esportes possuem representatividade internacional. O turismo rural é outra área que vem ganhando adeptos, aumentando as opções de renda com a utilização do cavalo. Minas Gerais e Bahia são os estados que possuem os maiores rebanhos, e a região CentroOeste é a que possui maior crescimento exponencial. Isso coloca o Brasil como um dos maiores efetivos do Mundo. O uso do cavalo ocupa diretamente mais de 640 mil pessoas no país, gerando de forma indireta 3,2 milhões de empregos e movimentando um montante de 7,5 bilhões de reais por ano na economia nacional (LIMA et al., 2012).

A criopreservação de sêmen iniciou-se há aproximadamente 60 anos com a descoberta do glicerol como crioprotetor. Essa descoberta permitiu que os espermatozoides fossem congelados, armazenados por tempo indeterminado e utilizados com sucesso na inseminação artificial. 
OLIVEIRA, R.A. Criopreservação de sêmen equino, um desafio a ser vencido. PUBVET, Londrina, V. 7, N. 26, Ed. 249, Art. 1647, Suplemento 2, 2013.

Além do melhoramento genético, o congelamento de sêmen serve como banco de reserva genética para animais de alto padrão racial e comercial, propicia maior intercâmbio entre criatórios das mais variadas regiões e países e seleciona indivíduos e linhagens quanto à sua fertilidade e congelabilidade. $\mathrm{A}$ criopreservação também contribui para minimizar perdas econômicas advindas da morte de reprodutores de alto valor comercial ou que participem de programas de revitalização de raças, para a preservação contra a extinção de raças nativas e conservação de espécies ameaçadas (WATSON, 2000).

$\mathrm{Na}$ equinocultura mundial é cada vez maior a utilização do sêmen congelado, devido a recente liberação do seu uso por grande parte das associações de criadores. Entretanto, a fertilidade do sêmen congelado ainda é baixa, e isto dificulta a sua utilização em larga escala (VIDAMENT, 2005; MILLER, 2008). As taxas de concepção por estro utilizando essa técnica variam bastante, sendo que em alguns garanhões chegam a oscilar entre $25 \mathrm{e}$ $40 \%$. Adicionalmente, sabe-se que boa parte dos garanhões não respondembem a essa biotécnica, o que faz com que o número de pesquisas nesse sentido venha aumentando cada vez mais, com o intuito de superar a variação individual (VIDAMENT, 2005).

Várias técnicas têm sido testadas para a criopreservação espermática utilizando diferentes velocidades e meios de centrifugação, curvas e meios de congelamento, crioprotetores e suas concentrações, bem como protocolos de descongelamento. Embora vários centros de pesquisa tenham se envolvido em estudos nesta área, ainda não há uma metodologia de congelamento universalmente aceita para esta espécie.

Objetivou-se com essa revisão reunir informações, e apresentá-las de forma sintética, sobre as principais limitações encontradas para criopreservação do sêmen de equinos e sua utilização em larga escala. 
OLIVEIRA, R.A. Criopreservação de sêmen equino, um desafio a ser vencido. PUBVET, Londrina, V. 7, N. 26, Ed. 249, Art. 1647, Suplemento 2, 2013.

\section{Criopreservação}

Para que o espermatozoide fertilize o oócito, deve preservar quatro atributos gerais após o congelamento e descongelamento: metabolismo para produção de energia; motilidade progressiva; enzimas, localizadas no acrossoma e proteínas na membrana plasmática, importantes para a sobrevivência do espermatozoide dentro do trato reprodutivo feminino e para a ligação do mesmo com a membrana plasmática do oócito para a fertilização. A destruição de componentes da célula espermática, associada com uma, ou mais dessas funções, reduzirá a fertilidade. Por exemplo, um espermatozoide móvel nem sempre é fértil; espermatozoides móveis usualmente têm adequada produção de energia, mas outro importante aspecto pode ter sido alterado (AMANN \& PICKETT, 1987).

O principal solvente biológico responsável pelo transporte de nutrientes e substâncias químicas é a água que, em seu estado puro, forma cristais a $0^{\circ} \mathrm{C}$, enquanto que, a que contém íons e outras substâncias em solução congela a temperaturas mais baixas, dependendo da concentração e natureza desses componentes (MAZUR, 1984).

Quando uma suspensão de espermatozoides é resfriada abaixo de $0^{\circ} \mathrm{C}$, cristais de gelo extracelulares começam a se formar. Isso resulta em aumento da concentração de sais no líquido extracelular. A proporção de água cristalizada como gelo e consequentemente a osmolaridade da solução remanescente, dependem da temperatura. Inicialmente a água do interior do espermatozóide não se congela, mas é resfriada abaixo do ponto de congelamento. A água se move do interior do espermatozoide para o meio extracelular, desidratando progressivamente a célula. Se a velocidade de congelamento é muito lenta, a alta concentração de sais intracelulares causada pela desidratação pode danificar o espermatozoide; se a taxa de congelamento for muito rápida, cristais de gelo intracelular podem se formar. A taxa de congelamento adequada é um equilíbrio entre esses fatores (MAZUR, 1984). 
OLIVEIRA, R.A. Criopreservação de sêmen equino, um desafio a ser vencido. PUBVET, Londrina, V. 7, N. 26, Ed. 249, Art. 1647, Suplemento 2, 2013.

Se a redução do volume celular atingir um mínimo crítico, a bicamada de fosfolipídeos da membrana celular fica muito comprimida e sua estrutura se quebra. Com isso, as funções de transporte e proteção da membrana não podem ser mantidas. Ao mesmo tempo, rupturas da membrana promovem uma ponte para entrada do gelo extracelular para o interior da célula. Dessa forma, para que uma substância tenha boa ação crioprotetora, deve atuar elevando a osmolaridade intracelular, para controlar a desidratação e ainda interagir com a membrana celular, estabilizando-a (AMANN \& PICKETT, 1987).

Dessa forma, os danos causados aos tecidos durante os processos de congelamento e descongelamento são devidos a: 1) Formação de cristais de gelo intracelulares, que afetam a estrutura da célula; 2) Concentração de soluto resultante do processo de desidratação, que ocorre durante o congelamento tanto no meio extra como intracelular e interação entre esses dois fatores. A natureza exata dos danos causados pelo congelamento aos tecidos, ainda não está totalmente esclarecida (AMANN \& PICKETT, 1987).

O mecanismo de ação dos crioprotetores, baseia-se principalmente na promoção da redução do ponto de solidificação da solução no congelamento, promovendo um maior tempo para a desidratação da célula, diminuindo a formação de cristais de gelo intracelulares (MAZUR, 1984).

Uma segunda função do crioprotetor é sua interação com a membrana celular exercendo ação estabilizadora durante as mudanças de um estado líquido para o sólido e vice-versa no descongelamento. Outra ação dos crioprotetores é a de diminuir os efeitos das altas concentrações osmóticas durante a desidratação celular. Muitas moléculas se dissolvem na mistura de crioprotetor e na água, tornando-se menos lesivas do que quando dissolvidas em altas concentrações em um líquido na ausência do crioprotetor (MAZUR, 1984).

Apesar dos efeitos benéficos do crioprotetor, não existe uma técnica de criopreservação celular que permita $100 \%$ de sobrevivência após o congelamento e descongelamento. Existem duas razões para justificar as falhas na ação dos crioprotetores: primeiro, a toxicidade do crioprotetor limita 
OLIVEIRA, R.A. Criopreservação de sêmen equino, um desafio a ser vencido. PUBVET, Londrina, V. 7, N. 26, Ed. 249, Art. 1647, Suplemento 2, 2013.

a concentração em que este pode ser utilizado antes do resfriamento e, portanto, limita a eficácia da ação crioprotetora, segundo, os agentes crioprotetores podem ter uma ação direta na produção de danos, alterando a polaridade do meio extracelular e lesando as membranas (FAHY, 1986).

Lesões espermáticas causadas pela criopreservação

O espermatozoide tem uma diversidade de atributos funcionais altamente diferenciados regionalmente que devem ser mantidos até a fertilização. A criopreservação ideal deve, então, ter o compromisso de preservar o maior número de células possível e a integridade de diferentes estruturas espermáticas (WATSON, 2000).

O resfriamento leva a célula a um estado de quiescência, reduz o metabolismo e proporciona diminuição nos gastos energéticos e na produção de catabólitos tóxicos, contribuindo para preservação celular. Da mesma maneira que o congelamento pode diminuir, ou paralisar algumas reações bioquímicas celulares, ele pode também acelerar outras, levando a danos ou mesmo morte celular (WATSON, 2000).

O termo estresse térmico, ou choque térmico define um conjunto de alterações ocorridas nos espermatozoides dos mamíferos quando resfriados da temperatura corpórea até temperaturas próximas a $5^{\circ} \mathrm{C}$, tendo como consequência um decréscimo irreversível da motilidade espermática, mudanças bioquímicas e na função espermática (AMANN \& PICKETT, 1987).

A redução da temperatura de $37^{\circ} \mathrm{C}$ a valores próximos de $4-5^{\circ} \mathrm{C}$ pode levar ao rearranjo de alguns fosfolípideos semelhantes dentro da bicamada da membrana plasmática, que podem agrupar-se e assumir outras configurações. Com este rearranjo, as propriedades biológicas básicas da membrana plasmática, como permeabilidade seletiva e difusão lateral de proteínas, não são mantidas, alterando a sua função (AMANN \& PICKETT, 1987).

A regulação do influxo de cálcio é claramente afetada pelo resfriamento, sendo, indiscutivelmente, uma das mais graves alterações em termos de 
OLIVEIRA, R.A. Criopreservação de sêmen equino, um desafio a ser vencido. PUBVET, Londrina, V. 7, N. 26, Ed. 249, Art. 1647, Suplemento 2, 2013.

função espermática, e, em alguns casos, esta alteração pode ser incompatível com a viabilidade espermática. A entrada de cálcio na célula durante o resfriamento, mimetizando o que ocorre fisiologicamente durante a capacitação, contribui para o início das reações fusogênicas entre a membrana plasmática e a membrana acrossomal externa (DOBRINSKI et al., 1997). WATSON (2000) relatou a existência de grande similaridade entre os danos verificados na membrana plasmática durante o congelamento e as alterações após a reação acrossomal.

Os principais fatores que afetam a fluidez característica da membrana plasmática são a composição relativa entre fosfolipídios e colesterol e a temperatura na qual a membrana é exposta. Com a queda da temperatura, os lipídeos passam pela transição de estado líquido para gelatinoso, onde as cadeias de ácidos graxos organizam-se em um modelo paralelo, ficando impossibilitados de se moverem aleatoriamente, resultando na formação de domínios cristalinos, com apenas pequenas regiões de lipídeos no estado líquido, onde ficam aderidas as proteínas, produzindo uma estrutura rígida. Deste modo, áreas da membrana plasmática tornam-se fracas, sujeitas a rupturas e permeáveis a íons, como o cálcio. Estes íons contribuem para mudanças no estado de capacitação e nos eventos fusionais, entre a membrana plasmática e a membrana acrossomal externa, característicos da reação acrossomal (HAMMERSTEDT et al., 1990).

A formação de cristais de gelo durante o congelamento descrita por MAZUR (1984) leva ao aumento da concentração de sais na fração não congelada que pode ser prejudicial ao espermatozoide. Altas concentrações de sais podem desidratar a célula espermática, deformando-a, provocando danos à estrutura da membrana, desestruturação e desnaturação das proteínas. Em conseqüência, os espermatozoides sofrem danos irreversíveis, caracterizados por movimentos anormais (circular ou retrógrado), rápida perda da motilidade, danos ao acrossoma e membrana plasmática, redução do metabolismo e perda de componentes intracelulares (AMANN \& PICKETT, 1987). 
OLIVEIRA, R.A. Criopreservação de sêmen equino, um desafio a ser vencido. PUBVET, Londrina, V. 7, N. 26, Ed. 249, Art. 1647, Suplemento 2, 2013.

Como o espermatozoide é resfriado na velocidade de $-25^{\circ} \mathrm{C}$ a $-40^{\circ} \mathrm{C} / \mathrm{min}$, a água intracelular não congelada se difunde para fora do espermatozóide devido ao aumento da concentração de solutos na fração de água não congelada extracelular. Isto causa a desidratação da célula com a possibilidade de danos devido à deformação celular, permanecendo desidratada até $-196^{\circ} \mathrm{C}$. No descongelamento, os cristais de gelo extracelulares se descongelam liberando água que dilui as concentrações de sais extracelulares e a água se difunde lentamente para o interior da célula. Este processo restaura o volume celular inicial e dilui as concentrações celulares de soluto aos valores originais (MAZUR, 1984; AMANN \& PICKETT, 1987).

Com o declínio constante da temperatura, as células ficam expostas à temperatura de congelamento, e com isto, os espermatozoides são submetidos a alterações de osmolaridade do meio que os circunda. A água presente no meio extracelular encontra-se sob a forma de solução, com o congelamento de parte desta água, a saturação de solutos aumenta, tornando hipertônico o meio externo. Neste momento, para que o equilíbrio osmótico seja atingido, ocorre efluxo de água da célula para o meio externo. Esta tentativa da célula de equilibrar-se com o meio que a circunda, pode conduzi-la a um efeito deletério devido a grande desidratação e a exposição a um meio extremamente saturado. É o chamado Efeito de Solução, considerado um dos pontos críticos no processo de congelamento das células espermáticas (MAZUR, 1984).

Interações dos componentes dos diluentes com a célula espermática

Diluentes são utilizados com o intuito de proteger os espermatozoides de todos os efeitos críticos do processo de congelamento. Para tanto, deverão ser adicionados, aos diluentes, macromoléculas como lipoproteínas e fosfolípideos que atuarão como estabilizadores da membrana plasmática assim também como crioprotetores. Deve-se ainda fornecer fonte de nutrientes para o metabolismo espermático e meio tampão para a manutenção do $\mathrm{pH}$. A 
OLIVEIRA, R.A. Criopreservação de sêmen equino, um desafio a ser vencido. PUBVET, Londrina, V. 7, N. 26, Ed. 249, Art. 1647, Suplemento 2, 2013.

produção de um diluente está sempre voltada para a obtenção de estabilização dos componentes da membrana plasmática (PARKS \& GRAHAM, 1992).

Existem diferenças na composição lipídica da membrana plasmática entre espécies, raças e ainda entre indivíduos da mesma espécie, sendo talvez, a explicação para que um mesmo meio diluente confira maior ou menor proteção aos espermatozoides de um determinado indivíduo (HOLT, 2000a). VIDAMENT et al. (1997) consideraram os garanhões como "bons congeladores" e "maus congeladores", e estas duas classes se diferenciam pela capacidade das células espermáticas tolerarem os efeitos deletérios da criopreservação.

Alguns componentes são essenciais no diluente como:

a) açúcares: Os açúcares têm sido incluídos nos diluentes para conservação de sêmen a baixas temperaturas como substrato de energia endógena, como componente osmótico e como agente crioprotetor em função do seu alto peso molecular, contribuindo para o equilíbrio osmótico atuando como substitutos de eletrólitos (HOLT, 2000a).

b) gema de ovo: O principal efeito protetor ocorre pela diminuição dos efeitos negativos do choque frio estabilizando as membranas espermáticas (HOLT, 2000a). Uma liproteína de baixa densidade encontrada na gema do ovo é o fator ativo que protege a célula espermática do choque frio, porém 0 mecanismo pelo qual este efeito se dá permanece não esclarecido (AMANN \& PICKETT, 1987) A gema de ovo pode conferir diversos graus de proteção aos espermatozóides de diferentes espécies animais, devido, principalmente, a comprovação da existência de distintas composições lipídicas das membranas plasmáticas entre as espécies animais (HOLT, 2000a).

c) leite: Duas substâncias são responsáveis por esta característica: a lactose, que age como elemento energético, e as proteínas do leite capazes de potencializar a atividade cinética dos espermatozóides. O leite é um líquido orgânico com importante propriedade biológica para a conservação das células; possui certa capacidade tampão, ação bactericida e viscosidade adequada para a manutenção dos espermatozóides no meio líquido com 
OLIVEIRA, R.A. Criopreservação de sêmen equino, um desafio a ser vencido. PUBVET, Londrina, V. 7, N. 26, Ed. 249, Art. 1647, Suplemento 2, 2013.

abundância de carboidratos que são utilizados pelas células na produção de energia (MANJUNATH, 2012).

d) tampões: O contínuo metabolismo espermático produz como resultado grandes quantidades de catabólitos tóxicos, acarretando aumento do ácido lático no meio extracelular. Este acúmulo pode causar a morte dos espermatozóides devido a drásticas alterações do pH no meio extracelular, justificando a necessidade de adição de tampões ao diluente (HOLT, 2000a). O fosfato foi primeiramente testado para este fim, porém o citrato de sódio adaptou-se melhor a esta finalidade. $\mathrm{O}$ citrato de sódio aumenta a capacidade de diluição da gema de ovo ao meio líquido, fenômeno que favorece a ação da gema sobre as células (HOLT, 2000b).

\section{Crioprotetor}

A adição de crioprotetores ao diluente é essencial para a sobrevivência das células espermáticas após os processos de resfriamento, porém os crioprotetores podem também acarretar danos às células (FAHY, 1986).

Os agentes crioprotetores são classificados em permeáveis e não permeáveis (MAZUR, 1984) à membrana citoplasmática. Os crioprotetores não permeáveis são representados por macromoléculas com alto peso molecular, como os açúcares,lipoproteínas da gema do ovo, proteínas do leite e alguns aminoácidos. Estas substâncias são responsáveis pelo mecanismo de proteção no meio extracelular, através de processo osmótico, promovem a desidratação celular durante o congelamento e impedem a formação de grandes cristais de gelo no interior da célula (HOLT, 2000a).

Os crioprotetores permeáveis exercem seu mecanismo de ação nos meios extracelular e intracelular; desempenham importante função no processo de criopreservação. Entre estes se destacam o glicerol (GLI), dimetilsulfóxido (DMSO), etilenoglicol (EG), propanodiol, butanodiol, metanol e amidas. A ação crioprotetora é atribuída a suas propriedades coligativas e ligantes com a água, diminuindo o ponto crioscópico intracelular. Isso aumenta 
OLIVEIRA, R.A. Criopreservação de sêmen equino, um desafio a ser vencido. PUBVET, Londrina, V. 7, N. 26, Ed. 249, Art. 1647, Suplemento 2, 2013.

a quantidade de água que permanece no estado líquido sob baixas temperaturas, diminuindo a concentração intracelular de solutos, retardando e limitando a formação dos cristais de gelo (HOLT, 2000b).

O glicerol é um crioprotetor essencial na maioria dos diluentes convencionais para congelamento de espermatozoides equinos. Durante o congelamento os espermatozoides são protegidos, uma vez que o GLI reduz a concentração de sais extracelulares durante o momento da desidratação e aumenta o percentual de água não congelada. Os espermatozoides são aparentemente sequestrados nos estreitos canais de água não congelada formada entre os grandes cristais de gelo (AMANN \& PICKETT, 1987).

A concentração de GLI utilizada nos diluentes exibe grande variação entre os trabalhos, de $2,5 \%$ a $7 \%$ (VIDAMENT, 2005). A concentração ideal de GLI para motilidade máxima pós-descongelamento para o espermatozoide equino ainda não foi encontrada, e pode diferir de acordo com a composição do diluente. No entanto VIDAMENT (2005) baseado em dados retrospectivos de 20 anos relata que $2,5 \%$ de GLI resultou em taxas de prenhez por ciclo satisfatórias, e que concentrações de 2 a 3\% também resultaram em índices de prenhez semelhantes.

O glicerol é o crioprotetor mais utilizado, mas tem efeitos tóxicos sobre os espermatozoides (FAHY, 1986), assim como efeito contraceptivo na égua reduzindo a fertilidade do sêmen equino quando incluído nos diluentes para sêmen fresco, resfriado e congelado (BEDFORD et al., 1995). No entanto o espermatozoide equino não consegue sobreviver ao congelamento sem um crioprotetor. Baseados nesses dados surgiram pesquisas para avaliar outros crioprotetores que fossem menos tóxicos ao espermatozoide do garanhão que o glicerol.

Crioprotetores alternativos foram testados por SQUIRES et al. (2004), como amidas (formamida (F), metilformamida (MF), dimetilformamida (DMF), acetamida (A) e metilacetamida (MA)), etilenoglicol, metilcelulose, rafinose e trealose para congelamento de sêmen de garanhões, desenvolvendo três experimentos. No experimento I avaliaram o efeito das amidas $(0,55 \mathrm{M})$ em 
OLIVEIRA, R.A. Criopreservação de sêmen equino, um desafio a ser vencido. PUBVET, Londrina, V. 7, N. 26, Ed. 249, Art. 1647, Suplemento 2, 2013.

comparação com o glicerol $(0,55 \mathrm{M})$. Os sptz foram analisados quanto a motilidade pós-descongelamento por avaliação computadorizada no tempos de 0, 15 e 30 minutos e quanto a integridade de membrana plasmática por citometria de fluxo. No experimento II avaliaram se os crioprotetores MF, DM e o EG, em três concentrações 0,3M, 0,6M e 0,9M, preservariam os espermatozoides tão efetivamente como o GLI a 0,55M. No experimento III avaliaram a MF $(0,9 \mathrm{M})$, pois apresentou os melhores resultados do experimento dois, na presença de crioprotetores não penetrantes como rafinose e trealose, isoladas ou em combinação com a metilcelulose.

No experimento I os autores não encontraram diferenças quanto ao percentual de sptz móveis em relação aos tempos das análises. Os sptz congelados com o GLI apresentaram maior percentual de espermatozoides com movimento total e progressivo, quando comparado com as amidas testadas, e a MF e DF resultaram em percentuais maiores que a $F$, A e a MA.

No experimento II SQUIRES et al. (2004) encontraram percentuais similares de espermatozoides móveis pós-descongelamento na presença de 0,6 e 0,9M de MF e DMF e 0,9M EG, quando comparado com 0,55M GLI. O percentual de espermatozoides viáveis foi similar para todos os crioprotetores, independente da concentração. No experimento III não houve diferença. Os autores concluíram que a MF e DMF protegem os espermatozoides dos danos ocasionados na criopreservação tanto quanto o glicerol. Portanto esses crioprotetores podem ser utilizados como alternativa para garanhões em que o sêmen congelado com o glicerol resulte em baixa motilidade pósdescongelamento.

Espermatozoides congelados com GLI e DMF foram avaliados in vitro e in vivo por VIDAMENT et al. (2002), e encontraram resultados de motilidade menores com $5 \%$ DMF do que quando associado a 3 ou $5 \%$ de GLI. A motilidade espermática foi maior quando utilizaram 1 e $3 \%$ de DMF associado com 1 e $3 \%$ de GLI. Concluindo que a associação de crioprotetores foi mais efetiva do que um crioprotetor. A taxa de prenhez foi similar para éguas 
OLIVEIRA, R.A. Criopreservação de sêmen equino, um desafio a ser vencido. PUBVET, Londrina, V. 7, N. 26, Ed. 249, Art. 1647, Suplemento 2, 2013.

inseminadas com $2 \%$ e $3 \%$ de GLI ( $46 \%$ e $58 \%$, respectivamente) comparada com $2 \%$ DMF (50\%).

Diversos agentes crioprotetores (dimetilsulfóxido, glicerol, etilenoglicol, dietilenoglicol e propilenoglicol) foram avaliados por CHENIER et al. (1998) na congelabilidade do sêmen de garanhões, não encontrando diferença entre GLI, EG e DMSO, no entanto o crioprotetor dimetilsulfoxido melhorou as características pós-descongelamento quando comparado com os outros tratamentos, e o etilenoglicol diminuiu a motilidade progressiva pósdescongelamento. O sêmen congelado com dietilenoglicol ou propilenoglicol mostrou significância, apresentando os índices de motilidade e viabilidade espermática mais baixos quando comparado aos outros crioprotetores. No teste de fertilidade sete das nove éguas (78\%) inseminadas com sêmen congelado com DMSO emprenharam.

Em pequisa para avaliar a integridade de membrana e motilidade do espermatozoide equino pós-descongelamento com diferentes crioprotetores, HENRY et al. (2002) compararam o efeito do GLI isolado ou associação com várias concentrações de etilenoglicol e acetamida. Entretanto quando um tratamento mostrou melhores resultados em um índice a mesma tendência não foi sustentada para outros. A utilização de qualquer um dos crioprotetores isolados ou em associação não resultou em melhora na viabilidade espermática pós-descongelamento quando comparado ao glicerol, concluindo que o etilenoglicol isolado ou em associação com glicerol e a acetamida podem ser utilizados como crioprotetores alternativos.

VIDAMENT (2005) cita esses trabalhos anteriores com a utilização de crioprotetores alternativos, como amidas e o etilenoglilcol, e propõe que mais estudos, incluindo testes de fertilidade seriam necessários antes de considerar a substituição do crioprotetor GLI. 
OLIVEIRA, R.A. Criopreservação de sêmen equino, um desafio a ser vencido. PUBVET, Londrina, V. 7, N. 26, Ed. 249, Art. 1647, Suplemento 2, 2013.

\section{Congelabilidade}

A congelabilidade do sêmen do garanhão é definida como o número de ejaculados selecionados pelo número total de ejaculados congelados. 0 ejaculado selecionado é aquele que apresenta uma motilidade progressiva $\geq 35 \%$ pós-descongelamento (VIDAMENT et al., 1997).

Avaliando a congelabilidade de 427 garanhões VIDAMENT et al. (1997) encontraram somente $20 \%$ apresentando resposta ao congelamento. A congelabilidade não varia somente entre garanhões mas também entre os ejaculados do mesmo garanhão. Os mecanismos que diferenciam um garanhão do outro quanto à resposta ao congelamento ainda não foram elucidados. Poderiam ser ou não de origem genética, e se fossem, a seleção genética de garanhões que apresentassem boa resposta ao congelamento seria um aspecto para seleção (SIEME et al., 2008).

Protocolos de diferentes países, métodos de congelamento e instruções para inseminação com sêmen congelado foram comparados por SIEME et al. (2008) e concluíram não haver um padrão, demonstrado por inúmeras diferenças no processamento do sêmen para criopreservação.

Para o congelamento realiza-se a coleta com auxílio de uma vagina artificial, com intervalos de $48 \mathrm{~h}$. Os protocolos de congelamento envolvem duas etapas de diluição do sêmen. A primeira diluição, para centrifugação, com uma solução salina/carboidrato ou leite desnatado, na proporção de 1:1 para separar os sptz do plasma seminal. A eficiência da centrifugação depende da duração (10-15 minutos) e da força de centrifugação (350-700 x g), 5-20\% de plasma seminal na suspensão após a centrifugação é essencial para sobrevivência dos sptz (SIEME et al., 2008).

A segunda diluição é realizada com o meio de congelamento contendo o crioprotetor. O glicerol é o crioprotetor universalmente utilizado, no entanto recentes pesquisas relatam a utilização de crioprotetores alternativos como o etilenoglicol, metilformamida, dimetilformamida e dimetilsulfóxido, com resultados similares ou superiores ao glicerol (SQUIRES et al., 2004; 
OLIVEIRA, R.A. Criopreservação de sêmen equino, um desafio a ser vencido. PUBVET, Londrina, V. 7, N. 26, Ed. 249, Art. 1647, Suplemento 2, 2013.

ALVARENGA et al., 2005). Entretanto, para VIDAMENT et al. (2002) não encontraram diferença na fertilidade do sêmen congelado de garanhões para os tratamentos GLI e DMF.

\section{Considerações finais}

O diluente centrifugação/congelamento, crioprotetor, sistema de armazenamento, ou método de congelamento interferem de forma fundamental na fertilidade do sêmen congelado, além de outros fatores, como protocolos de inseminação artificial e fertilidade da égua.

A comparação entre trabalhos é extremamente difícil, pois com raras exceções se encontram trabalhos na literatura com a mesma metodologia de congelamento. Devido a diferenças entre raças, entre garanhões e até entre diferentes ejaculados do mesmo garanhão, ainda não existe um protocolo eficiente de congelamento.

Com a crescente procura desta biotécnica pelos produtores, é cada vez maior a necessidade de protocolos de congelamento e inseminação que proporcionem taxas de fertilidade superiores, para que a credibilidade desta técnica e sua utilização tornem-se rotineiras nos criatórios.

\section{Referências}

1. AlVARengA, M.A.; PAPA, F.O.; LANDiM-ALVARENGA, F.C.; MEDEIROS, A.S.L. Amides as cryoprotectants for freezing stallion semen: A review. Animal Reproduction Science, v.89, p.105-113, 2005.

2. AMANN, R.P.; PICKETT, B.W. Principles of cryopreservation and review of cryopreservation of stallion spermatozoa. Journal of Equine Veterinary Science, v.7, p.145-173, 1987.

3. BEDFORD, S.J.; JASKO, D.J.; GRAHAM, J.K.; AMANN, R.P.; SQUIRES, E.L.; PICKETT, B.W. Effect of seminal extenders containing egg yolk and glycerol on motion characteristics and fertility of stallion spermatozoa. Theriogenology, v.43, p.955-967, 1995.

4. CHENIER, T.; MERKIES, K.; LEIBO, S.; PLANTE, C.; JOHNSON, J. Evaluation of cryoprotective agents for use in the cryopreservation of equine spermatozoa. In: ANNUAL AMERICAN ASSOCIATION OF EQUINE PRACTITIONERS CONVENTION, 44., 1998, Baltimore., Anais...Lexington: AAEP, 1998. p.5-6. 
5. DOBRINSKI, I.; THOMAS, P.G.A.; BALL, B.A. Cryopreservation reduces the ability of equine sperm to attach to oviductal epithelial cells and zonapellucida. Journal of Andrology, v.16, p.536-542, 1995.

6. DOBRINSKI, I.; SMITH, T.T.; SUAREZ, S.S.; BALL, B.A. Membrane contact with oviductal epithelium modulates the intracellular calcium concentration of equine spermatozoa in vitro. Biology of Reproduction, v.56, p.861-869, 1997.

7. FAHY, G.M. The relevance of cryoprotectant "toxicity" to cryobiology. Cryobiology, v.23, p.1-13, 1986.

8. HAMMERSTEDT, R.H.; GRAHAM, J.K.; NOLAM, J.P. Cryopreservation of mammalian sperm: What we ask them to survive? Journal of Andrology, v.11, p.73-88, 1990.

9. HENRY, M.; SNOECK, P.P.N.; COTTORELLO, A.C.P. Post-thaw spermatozoa plasma membrane integrity and motility of stallion semen frozen with different cryoprotectants. Theriogenology, v.58, p.245-248, 2002.

10. HOLT, W.V. Basic aspects of frozen storage of semen. Animal Reproduction Science, v.62, p.3-22, 2000a.

11. HOLT, W.V. Fundamental aspects of sperm cryobiology: The importance of species and individual differences. Theriogenology, v.53, p.47-58, 2000b.

12. LimA, R. A. S.; OliveirA, R. A. MENDES, C. Q.; JúniOR, P. G. Perfil e Tendências da Equideocultura Brasileira. Anais da 49a Reunião Anual da Sociedade Brasileira de Zootecnia. A produção animal no mundo em transformação. Brasília, 23 a 26 de julho de 2012.

13. MANJUNATH, P. New insights into the understanding of the mechanism of sperm protection by extender components.Animal Reproduction Science, v.9, p.809-815, 2012.

14. MAZUR, P. Freezing of living cells: mechanisms and implications. TheAmerican Journal of Physiology, v.247, p.125-142, 1984.

15. MILLER, C.D. Optimizing the use of frozen-thawed equine semen. Theriogenology, v.70, p.463-468, 2008.

16. PARKS, J.E.; GRAHAM, J.K. Effects of cryopreservation procedures on sperm membranes. Theriogenology, v.38, p.209-222, 1992.

17. SIEME, H.; HARRISON, R.A.P.; PETRUNKINA, A.M. Cryobiological determinants of frozen semen quality, with special reference to stallion. Animal Reproduction Science, v.107, p.276-292, 2008.

18. SQUIRES, E.L.; KEITH, S.L.; GRAHAM, J.K. Evaluation of alternative cryoprotectants for preserving stallion spermatozoa. Theriogenology, v.62, p.1056-1065, 2004.

19. VIDAMENT, M.; DUPERE, A.M.; JULIENNE, P.; EVAIN, A.; NOUE, P.; PALMER, E. Equine frozen semen: freezability and fertility field results. Theriogenology, v.48, p.907-917, 1997.

20. VIDAMENT, M.; DAIRE, C.; YVON, J.M.; DOLIGEZ, P.; BRUNEAU, B.; MAGISTRINI, M.; ECOT, P. Motility and fertility of stallion semen frozen with glycerol and/or dimethyl formamide. Theriogenology, v.58, p. 249-251, 2002.

21. VIDAMENT, M. French field results (1985-2005) on factors affecting fertility of frozen stallion semen. Animal Reproduction Science, v.89, p.115-136, 2005.

22. WATSON, P.F. The causes of reduced fertility with cryopreserved semen.Animal Reproduction Science, v.60-61, p.481-492, 2000. 